\section{Military Technical College Kobry El-Kobbah, Cairo, Egypt}

\author{
$8^{\text {th }}$ International Conference \\ on Electrical Engineering \\ ICEENG 2012
}

\title{
Load shedding as a corrective action against voltage collapse
}

$$
\text { By }
$$
A. Y. Abdelaziz*
A. T. M. Taha*
M. A. Mostafa*
A. M. Hassan*

\section{$\underline{\text { Abstract: }}$}

The phenomenon of voltage collapse eclipses a potential hazard for the transmission and distribution systems. The load shedding for avoiding the existence of voltage instability in power systems is taken as a remedial action during emergency states. The load shedding strategy for power systems with location and quantity of load to be shed is presented in this paper. Two methods are used for this purpose. The first method is based on a mathematical calculation of an indicator of risk of voltage instability. The second method is based on a fuzzy load shedding based algorithm that uses a voltage stability indicator for averting voltage collapse. Applications to the standard IEEE 14bus system are presented to validate the applicability of the two proposed methods.

\section{Keywords:}

Load Shedding, Voltage Instability, L-indicator, Fuzzy logic

* Electrical Power and Machines Department, Faculty of Engineering, Ain Shams University, Cairo, Egypt 


\section{Introduction:}

The phenomenon of voltage collapse on a transmission and distribution systems is often caused by a low voltage initial profile, excessive demand, operation near to maximum power to be transmitted, generating facilities located too far from demand or insufficiency of reactive power compensation facilities [1]. At first a gradual voltage drop in one or several consumer regions may lead to increase reactive losses in the system and push transformer taps towards maximum values. Some generators can reach their limits of reactive power. Then voltage drops rapidly and it may drop so far as to cascade tripping of on-line generators thus causing a complete collapse of the system [2].

When the operating state is near instability, the main objective is prevention of voltage collapse. If all the control strategies such as rescheduling of generations, bringing standby generators on-line, switching capacitor banks, reduction of voltage magnitude set point and other reactive power controls are exhausted; the only alternative way is load curtailment at some weak buses to avoid voltage collapse. The contribution of the effect of load shedding to avoid voltage instability is reported in [3-6].

The aim of this work is to build a tool to help operators in an emergency by proposing load shedding actions. The phenomenon of voltage collapse is very complicated. An exact calculation to estimate voltage stability limits is difficult. Furthermore, when it happens the process evolves very quickly [6]. In order to try to identify on-line a risk of voltage instability (RVI) a rapid indicator is needed. If necessary, emergency measures to avoid all risks must be quickly proposed.

Several authors have worked on load shedding to avoid the risk of voltage instability. In [7], a fast calculation of indicators of risk of voltage instability has been developed. These indicators can detect on-line voltage instability and signal the tendency towards a critical situation. Their values change between zero (no load) and one (voltage collapse). In [8], a concept for under voltage load shedding is presented. In the event of an approaching blackout (collapse), it is difficult to ensure voltage stability and reacceleration of motors by reactive power compensation alone. Hence counter measure required to avoid voltage collapse is the shedding of loads. Under-voltage load shedding is powerful countermeasure to maintain voltage stability for severe contingencies $[9$, 10].

Power systems are large networks that are subjected to unexpected events and in some cases, the uncertainties are probabilistically represented. Therefore, fuzzy logic techniques offer good tools applicable for power system problems [11, 12]. In [13], two fuzzy based load shedding methods that use a voltage stability indicator for averting voltage collapse are proposed. The first method identifies the most appropriate locations and uses an analytical procedure to compute the sheddable load, while the second directly predicts the amount of load to be shed at the critical buses. 
In this paper, two algorithms for determining the load to be shed and location in order to avoid risks of voltage instability are presented. The first method is based on the calculation of indicator of risk of voltage instability. The aim of this method is to obtain through load shedding an indicator profile lower than a threshold value in order to ensure that the power system will remain in a state far from voltage instability point. The load bus (location) where the indicator is the highest is selected in order to carryout load shedding. A relation between indicator changes and load powers to be shed is developed. With help of this relation the amount of load to be shed can be determined. The second method is based on the fuzzy logic technique which determines the suitability of each bus for load shedding one by one and the bus with the highest suitable value is chosen as the most appropriate bus for load shedding. The amount of load to be shed is then calculated at the chosen bus. The two methods are applied to the standard IEEE 14-bus system.

\section{Mathematical calculation for load shedding using voltage stability indicator:}

In $[7,14]$, voltage stability indicator at bus $\mathrm{j}$ can be determined by:

$$
L_{j}=\left|1-\frac{\sum_{i \in \alpha G} F_{j i} V_{i}}{V_{j}}\right| \quad j \in \alpha L
$$

Where,

$\alpha_{\mathrm{L}}$ : Set of load buses.

$\alpha_{\mathrm{G}}$ : Set of generator buses.

$\mathrm{V}_{\mathrm{i}}$ : Voltage of generator bus i.

$\mathrm{V}_{\mathrm{j}}$ : Voltage of load bus $\mathrm{j}$.

$$
\begin{aligned}
& {[\mathrm{Y}]=\left[\begin{array}{ll}
\mathrm{Y}_{\mathrm{GG}} & \mathrm{Y}_{\mathrm{GL}} \\
\mathrm{Y}_{\mathrm{LG}} & \mathrm{Y}_{\mathrm{LL}}
\end{array}\right]} \\
& {[\mathrm{F}]=-\left[\mathrm{Y}_{\mathrm{LL}}\right]^{-1}\left[\mathrm{Y}_{\mathrm{LG}}\right]}
\end{aligned}
$$

$\mathrm{Y}_{\mathrm{GG}}, \mathrm{Y}_{\mathrm{LL}}, \mathrm{Y}_{\mathrm{LG}}, \mathrm{Y}_{\mathrm{GL}}$ : Elements of system admittance matrix

[Y]: Bus admittance Matrix

$\left[\mathrm{Y}_{\mathrm{GG}}\right]$ : Sub-matrix with dimension $(\mathrm{g} \mathrm{x} \mathrm{g})$.

$\left[\mathrm{Y}_{\mathrm{GL}}\right]$ : Sub-matrix with dimension $(\mathrm{g} x(\mathrm{n}-\mathrm{g}))$.

$\left[Y_{L G}\right]$ : Sub-matrix with dimension $((n-g) x g)$.

$\left[Y_{L L}\right]$ : Sub-matrix with dimension $((n-g) x(n-g))$ 
A global voltage stability indicator of a power system is given by L, $0 \leq \mathrm{L} \leq 1$

0 : far away from voltage instability point

1: at voltage stability point

The indicator at bus $\mathrm{j}$ determined by equation (1) can be separated into real and imaginary part

$$
\begin{aligned}
& \mathrm{L}_{\mathrm{j}}^{\mathrm{R}}=1-\frac{\sum_{\mathrm{i} \in \alpha \mathrm{G}}\left|\mathrm{F}_{\mathrm{ji}}\right|\left|\mathrm{V}_{\mathrm{i}}\right| \cos \mid \theta_{\mathrm{ji}}+\delta_{\mathrm{i}}-\delta_{\mathrm{j}}}{\left|\mathrm{V}_{\mathrm{j}}\right|} \\
& \mathrm{L}_{\mathrm{j}}^{\mathrm{I}}=-\frac{\sum_{\mathrm{i} \in \alpha \mathrm{G}}\left|\mathrm{F}_{\mathrm{ji}}\right|\left|\mathrm{V}_{\mathrm{i}}\right| \sin \mid \theta_{\mathrm{ji}}+\delta_{\mathrm{i}}-\delta_{\mathrm{j}}}{\left|\mathrm{V}_{\mathrm{j}}\right|}
\end{aligned}
$$

The voltage stability indicator at each bus is a function of voltage angles and magnitudes, the real and imaginary parts of indicators can be expressed as:

$$
\begin{aligned}
& \mathrm{L}^{\mathrm{I}}=\mathrm{F}_{1} \quad(\delta,|\mathrm{V}|) \\
& \mathrm{L}^{\mathrm{R}}=\mathrm{F}_{2}(\delta,|\mathrm{V}|)
\end{aligned}
$$

The partial derivative of equations (4) and (5) with respect to voltage angle and magnitude changes can be determined as:

$$
\frac{\partial_{j}^{I}}{\partial \delta \mathrm{j}}=\frac{\sum_{\mathrm{i} \in \alpha \mathrm{G}}\left|\mathrm{F}_{\mathrm{ji}}\right|\left|\mathrm{V}_{\mathrm{i}}\right| \cos \left(\theta_{\mathrm{ji}}+\delta_{\mathrm{i}}-\delta_{\mathrm{j}}\right)}{\left|\mathrm{V}_{\mathrm{j}}\right|}=-\left(\mathrm{L}_{\mathrm{j}}^{\mathrm{R}}-1\right)
$$

Matrix $[\mathrm{T}]$ is the sensitivity matrix between indicator changes and voltage angle and magnitude changes. This matrix is very sparse and large number of coefficients of this matrix is not needed. The necessary coefficients to be used for calculations are those located in the row associated with bus $\mathrm{J}$ (if bus $\mathrm{J}$ is selected to carryout load shedding) [6].

Coefficient of matrix $[\mathrm{T}]$ can be determined as: 


$$
\begin{aligned}
& \frac{\partial L_{j}^{I}}{\partial \delta \mathrm{j}}=\frac{\sum_{\mathrm{i} \in \alpha \mathrm{G}}\left|\mathrm{F}_{\mathrm{ji}}\right|\left|\mathrm{V}_{\mathrm{i}}\right| \cos \left(\theta_{\mathrm{ji}}+\delta_{\mathrm{i}}-\delta_{\mathrm{j}}\right)}{\left|\mathrm{V}_{\mathrm{j}}\right|}=\left(\mathrm{L}_{\mathrm{j}}^{\mathrm{R}}-1\right) \\
& \frac{\partial L_{j}^{R}}{\partial \delta_{i}}=\frac{\sum_{i \in O G}\left|F_{j i}\right|\left|V_{i}\right| \sin \left(\theta_{j i}+\delta_{i}-\delta_{j}\right)}{\left|V_{j}\right|}=L_{j}^{I} \\
& \frac{\partial_{\mathrm{j}}^{\mathrm{R}}}{d \mathrm{~V}_{\mathrm{j}} \mid}=\frac{\sum_{\mathrm{i} \in \alpha \mathrm{G}}\left|\mathrm{F}_{\mathrm{j}}\right||\mathrm{V}| \cos \left(\theta_{\mathrm{ji}}+\delta_{\mathrm{i}}-\delta_{\mathrm{j}}\right)}{\left|\mathrm{V}_{\mathrm{j}}\right|^{2}}=\frac{\mathrm{I}_{\mathrm{j}}^{\mathrm{R}}-1}{\left|\mathrm{~V}_{\mathrm{j}}\right|} \\
& \frac{\partial_{\mathrm{j}}^{\mathrm{I}}}{\partial \mathrm{V}_{\mathrm{j}} \mid}=\frac{\sum_{\mathrm{i} \in \mathrm{OG}}\left|\mathrm{F}_{\mathrm{ji}}\right|\left|\mathrm{V}_{\mathrm{i}}\right| \sin \left(\theta_{\mathrm{ji}}+\delta_{\mathrm{i}}-\delta_{\mathrm{j}}\right)}{\left|\mathrm{V}_{\mathrm{j}}\right|^{2}}=\frac{\mathrm{I}_{\mathrm{j}}^{\mathrm{I}}}{\left|\mathrm{V}_{\mathrm{j}}\right|}
\end{aligned}
$$

From conventional Newton-Raphson load flow, we obtain a linear relation between changes in voltage phase/magnitudes and active/reactive power injections.

$$
\left[\begin{array}{l}
\Delta \delta \\
\Delta|\mathrm{V}|
\end{array}\right]=[\mathrm{J}]^{-1}\left[\begin{array}{c}
\Delta \mathrm{P} \\
\Delta \mathrm{Q}
\end{array}\right]
$$

By substituting from (13) in (8), we get a relationship between real and imaginary parts of indicators and injected power as seen below:

$$
\left[\begin{array}{c}
\Delta \mathrm{L}^{\mathrm{I}} \\
\Delta \mathrm{L}^{\mathrm{R}}
\end{array}\right]=[\mathrm{T}][\mathrm{J}]^{-1}\left[\begin{array}{c}
\Delta \mathrm{P} \\
\Delta \mathrm{Q}
\end{array}\right]
$$

A relationship between changes in indicators at load bus $\mathrm{j}$ and power injections at all load buses can be obtained:

$$
\begin{aligned}
\Delta \mathrm{L}_{\mathrm{j}}^{\mathrm{I}} & =\mathrm{S}_{11} \Delta \mathrm{P}_{\mathrm{j}}+\mathrm{S}_{12} \Delta \mathrm{Q}_{\mathrm{j}} . \\
\Delta \mathrm{L}_{\mathrm{j}}^{\mathrm{R}} & =\mathrm{S}_{21} \Delta \mathrm{P}_{\mathrm{j}}+\mathrm{S}_{22} \Delta \mathrm{Q}_{\mathrm{j}}
\end{aligned}
$$


Where $[\mathrm{J}]$ is the power flow Jacobian matrix; $[\mathrm{P}]$ and $[\mathrm{Q}]$ are the real and reactive power mismatches; $[\mathrm{S}]=[\mathrm{T}][\mathrm{J}]^{-1}$ (Appendix 1).

The active and reactive loads are not independent: one cannot shed active loads without reducing reactive loads. Usually a relation between active and reactive load can be obtained as follows. Here the load power factor is assumed to be constant at each load bus.

$$
\begin{aligned}
& \operatorname{Pf}_{j}=\frac{Q_{j}}{P_{j}} \quad j \in \alpha_{L} \\
& P f_{j}=\frac{\Delta Q_{j}}{\Delta P_{j}} \\
& \Delta Q_{j}=P f_{j} \Delta P_{j}
\end{aligned}
$$

By substituting from (17) in (15 \& 16), a relationship between changes of the indicator at bus $\mathrm{j}$ and changes in active power injected at the same bus can be obtained as:

$$
\begin{aligned}
& \mathrm{S}_{1}=\mathrm{S}_{11}+\mathrm{S}_{12} \mathrm{Pf}_{\mathrm{j}} \\
& \mathrm{S}_{2}=\mathrm{S}_{21}+\mathrm{S}_{22} \mathrm{Pf}_{\mathrm{j}}
\end{aligned}
$$

Using equations (18) and (19), active / reactive amount of load to be shed can be determined as:

$$
\begin{aligned}
& \Delta \mathrm{P}_{\mathrm{j}}=\frac{\Delta \mathrm{L}_{\mathrm{j}}}{\sqrt{\left(\mathrm{S}_{1}{ }^{2}+\mathrm{S}_{2}{ }^{2}\right)}} \\
& \Delta \mathrm{Q}_{\mathrm{j}}=\mathrm{Pf}_{\mathrm{j}} \Delta \mathrm{P}_{\mathrm{j}}
\end{aligned}
$$

Where,

$\Delta \mathrm{L}_{\mathrm{j}}$ : The change of L-Indicator index required at critical bus-j to bring the system away from instability point.

$\Delta \mathrm{L}_{\mathrm{j}}=\mathrm{L}_{\mathrm{j}}-\mathrm{TV}$

$\mathrm{TV}=$ threshold value

\subsection{Algorithm for calculation of the load to be shed:}

Fig. 1 shows a flow chart for the algorithm that is used in the paper to calculate the load to be shed using the $\mathrm{L}$ indicator. 


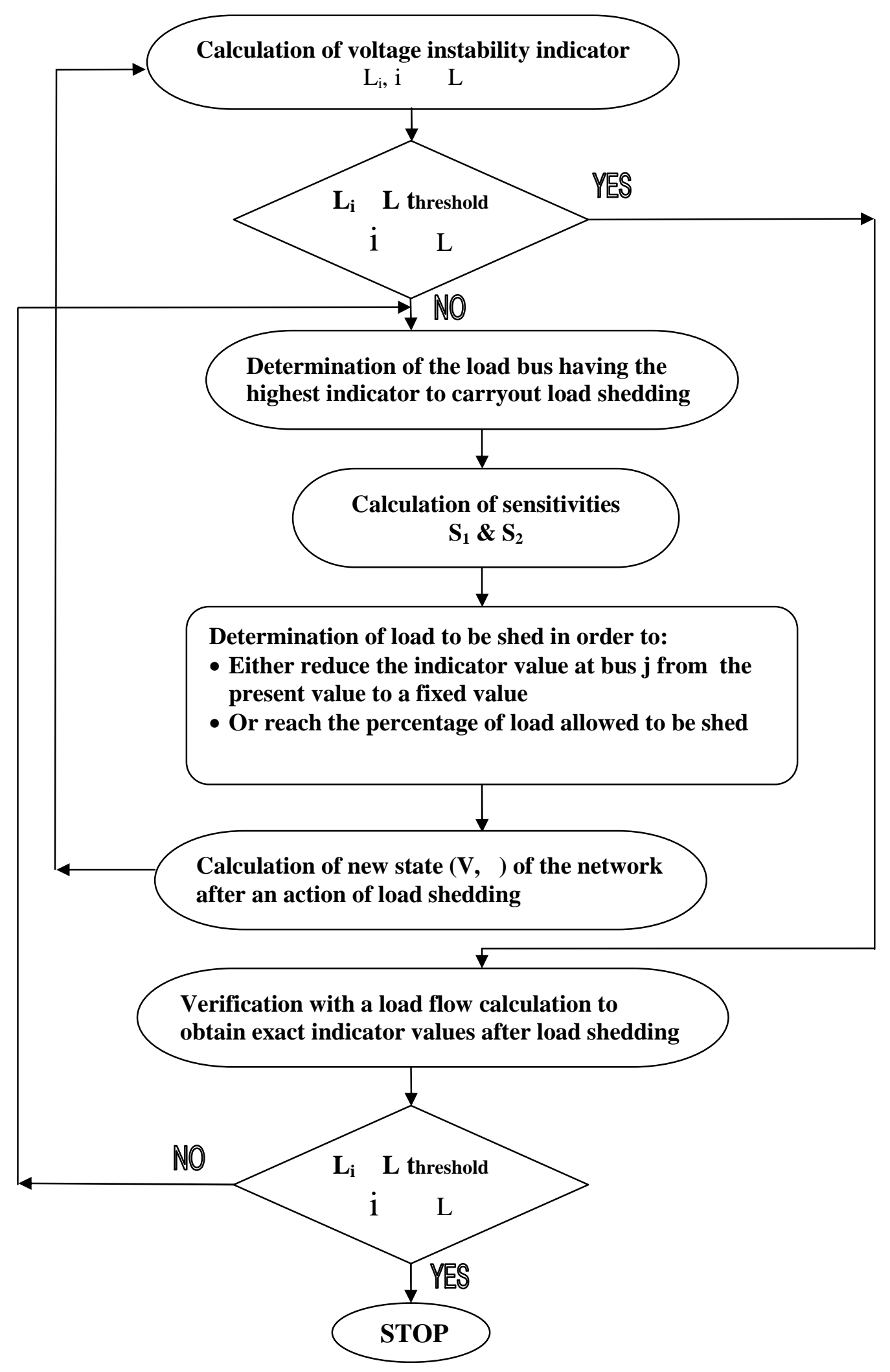

Figure (1): Algorithm for the calculation of load to be shed. 


\section{Fuzzy based load shedding scheme:}

Power systems are large networks that are subjected to unexpected events and in some cases, the uncertainties are probabilistically represented. However, it is made clear that some of the uncertain functions are intrinsically fuzzy in nature and difficult to handle effectively by probability. Fuzzy set theories offer a compromise in the sense of better solutions can be found that cannot be easily determined by other methods and are readily applicable to power system problems [11, 12].

The proposed fuzzy logic system (FLS) determines the suitability of each bus for load shedding one by one and the bus with the highest suitable value is chosen as the most appropriate bus for load shedding. The amount of load to be shed is then calculated at the chosen bus. The chosen input linguistic variables are Voltage instability L index, Voltage Magnitude (VM) and the output variable is Selected Bus for Load Shedding (SBLS).

The rules are summarised in the fuzzy decision matrix shown in Table 1 and Table 2. The consequents of the rules are shown in the shaded part of the matrix. Having related the input variables to the output variable, the fuzzy results are defuzzified through what is called a defuzzification process, to achieve a crisp numerical value, the most commonly used centroid. The RVI values are calculated for the load buses from the power flow solution. The fuzzy scheme is allowed to determine the suitability of each bus and the one with the highest suitability chosen for load shedding.

The FIS Editor displays general information about the fuzzy inference system.

The FIS Editor is illustrated at Fig. 2 and Fig. 3.

Fuzzy Rules Matrix

Inputs: $\mathrm{L}_{\mathrm{i}}$ (Voltage instability index) Trapezoidal membership function (Fig. 4)

VM (Voltage Magnitude) Triangle membership function as shown in Fig. 5

Output: SBLS (Selected Bus Load Shedding) Triangle membership function as shown in Fig. 6.

Table 1: Selected bus for load shedding decision matrix

Fuzzy decision matrix.

\begin{tabular}{lllllll}
\hline \multirow{2}{*}{ AND } & & VM & & & & \\
\cline { 3 - 7 } & & L & LM & M & HM & H \\
\hline \multirow{2}{*}{} & Li & LM & LM & L & L & L \\
& M & M & LM & LM & L & L \\
& M & M & LM & LM & L \\
& HM & M & M & LM & LM \\
& H & H & HM & M & M & LM \\
\hline
\end{tabular}


Inputs: $\Delta \mathrm{Li}$ (Change in Voltage instability index) Trapezoidal Member ship function

VM (Voltage Magnitude) Triangle membership function

Output: SL (Sheddable load) Triangle membership function as shown in Fig. 6.

SL: represents a part of real power sheddable load, the reactive component of the sheddable load can be calculated by treating the power factor constant. The power factor angle is calculated from the specified real and reactive power load at each bus.

Table 2: Sheddable load decision matrix

Fuzzy decision matrix.

\begin{tabular}{lllllll}
\hline \multirow{2}{*}{ AND } & & VM & & & & \\
\cline { 3 - 7 } & & L & LM & M & HM & H \\
\hline \multirow{3}{*}{$\Delta \mathrm{Li}_{\mathrm{i}}$} & L & LM & LM & L & L & L \\
& M & M & LM & LM & L & L \\
& H & HM & M & LM & LM & L \\
& H & H & HM & M & LM & LM \\
& & & & & M & LM \\
\hline
\end{tabular}

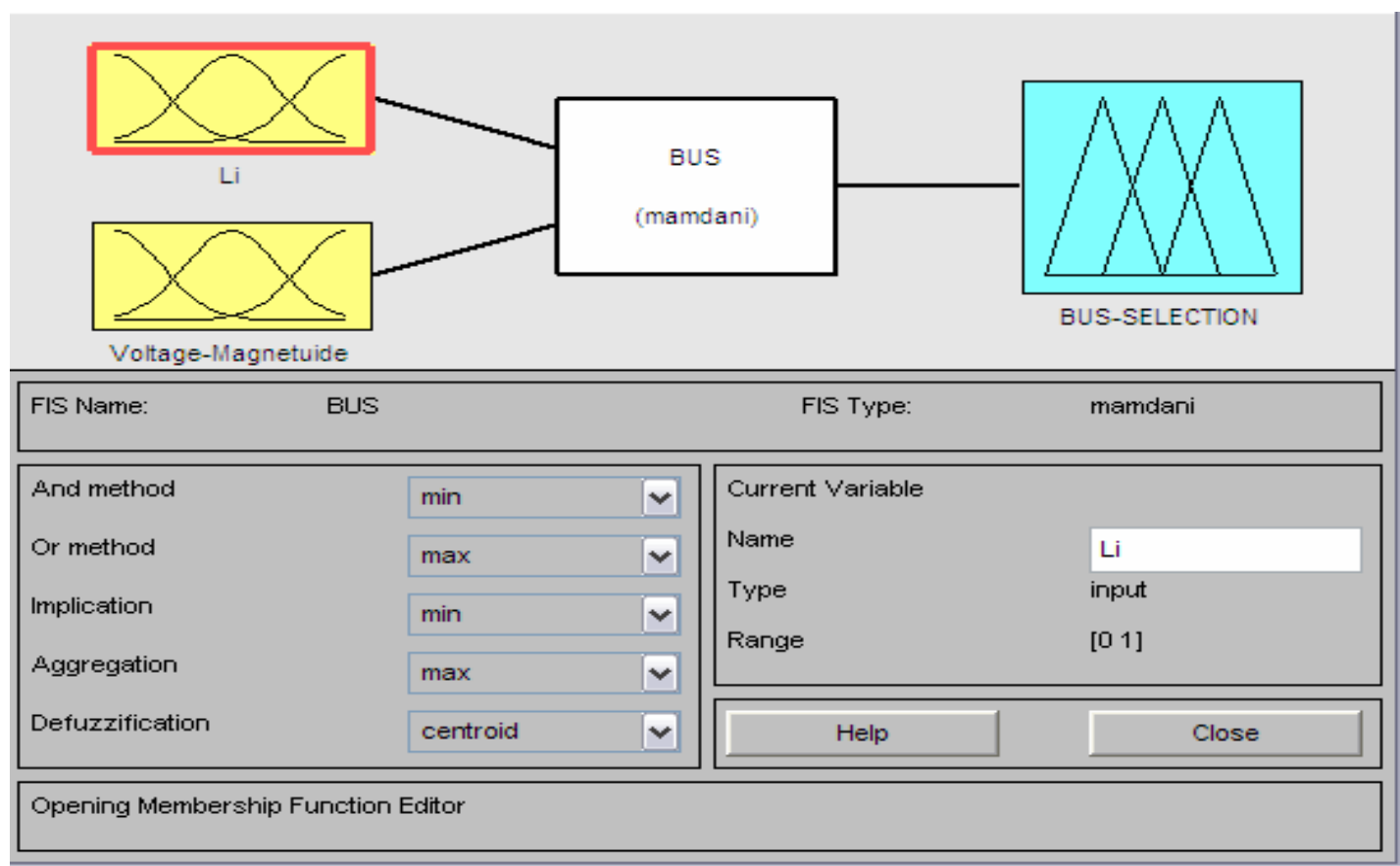

Figure 2: Bus selection FIS Editor 
The framework of proposed method excludes the use of numerical procedures and relies solely on fuzzy logic. The Li index is calculated at every bus from the results of the load flow solution. The approach is designed so as to calculate the amount of sheddable real and reactive power loads at the chosen bus for load shedding, where the RVI value is the largest and exceeds the threshold value. So, the input variables are Change of $L_{i}$ index required at critical bus-j to bring the system away from instability point. VM of critical bus-j and the output variable is SLj, "amount of load to be shed".

The Fuzzy Logic System is used to determine the amount of real and reactive powers to be shed at the chosen load bus. The computed load is allowed to be shed and the above process is continued till either all the $\mathrm{Li}$ indicator values are less than a selected threshold value or all the load buses approach their respective sheddable limit.

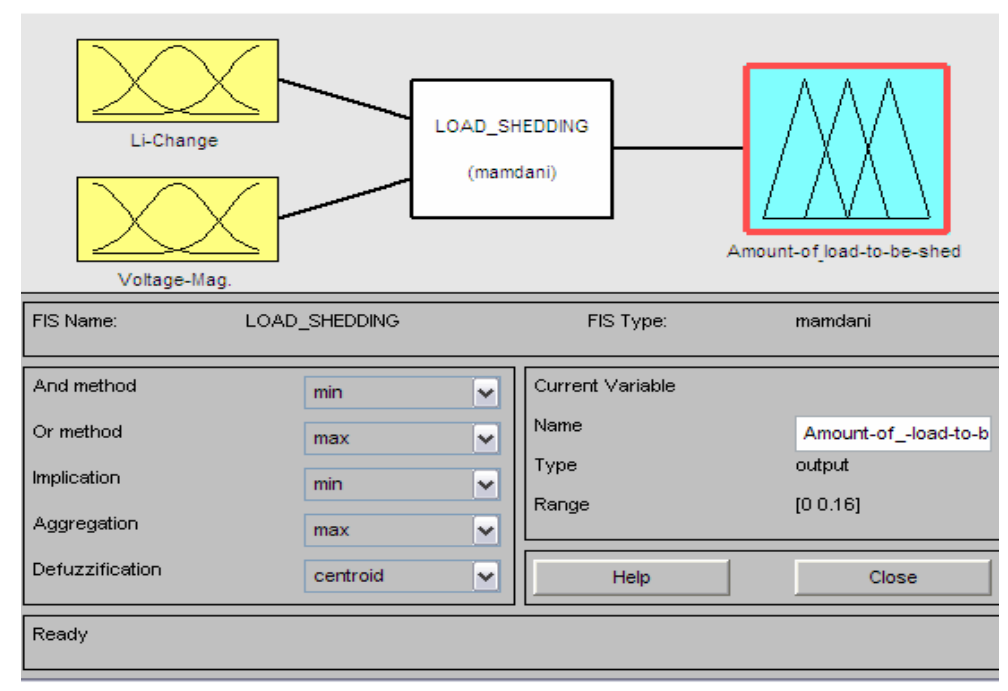

Figure 3: Load shedding FIS Editor

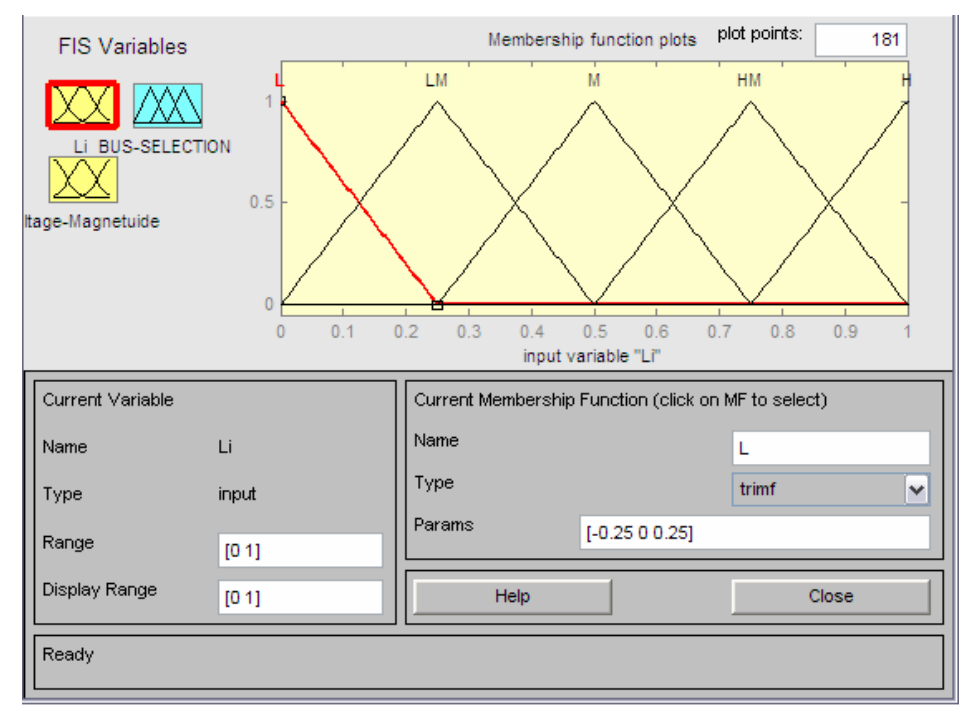

Figure 4: The input variable - $\left(L_{i}\right)$ membership function 


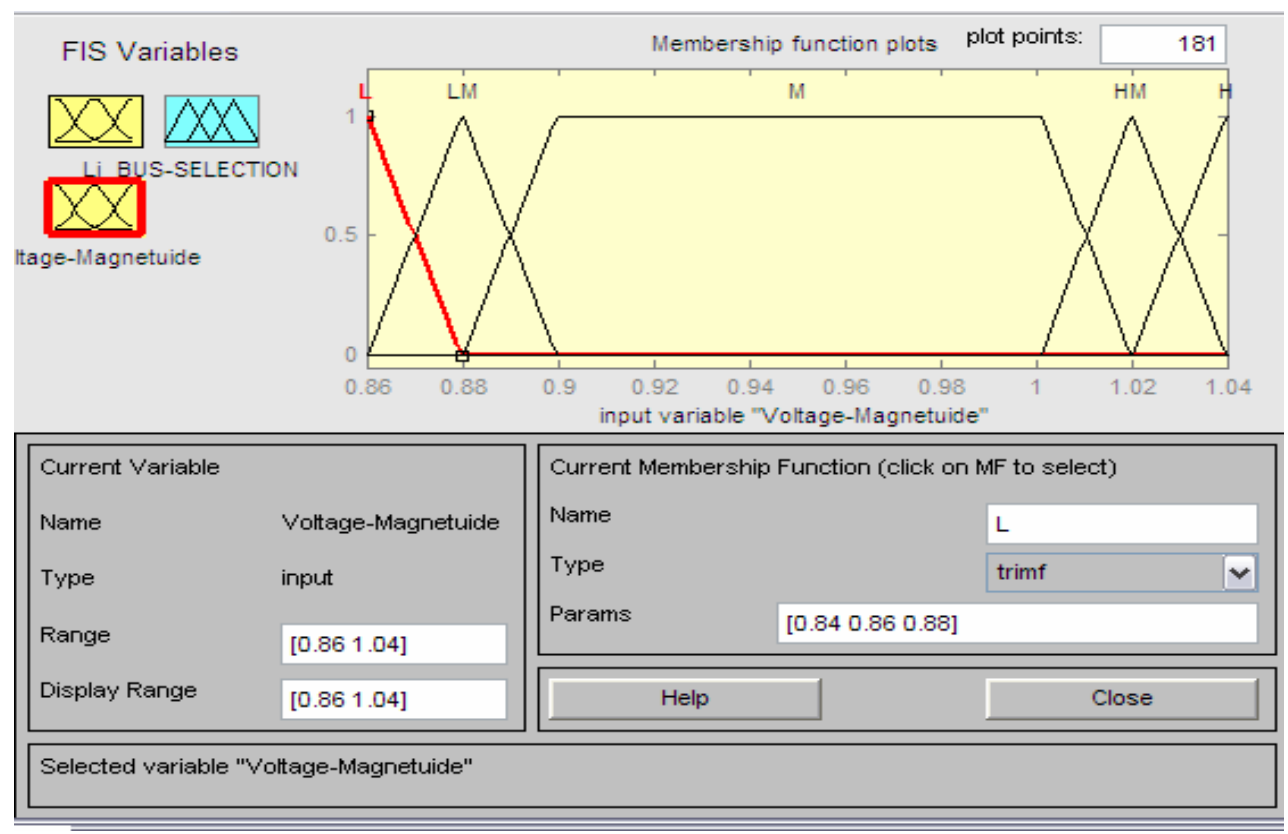

Figure 5: The input variable - Voltage Magnitude (VM) membership function

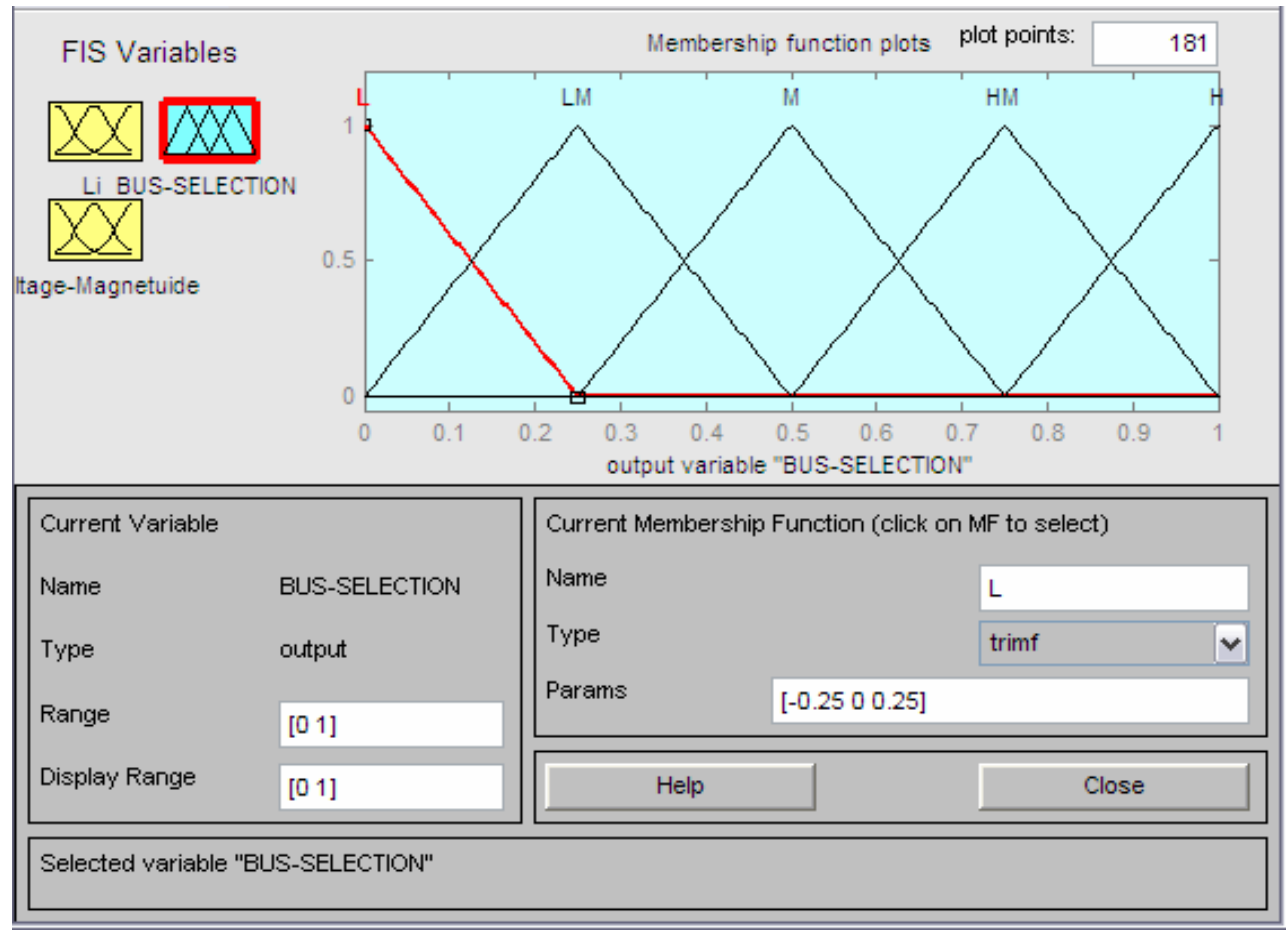

Figure 6: The output variable - Selected bus for load shedding (SBLS) membership function 


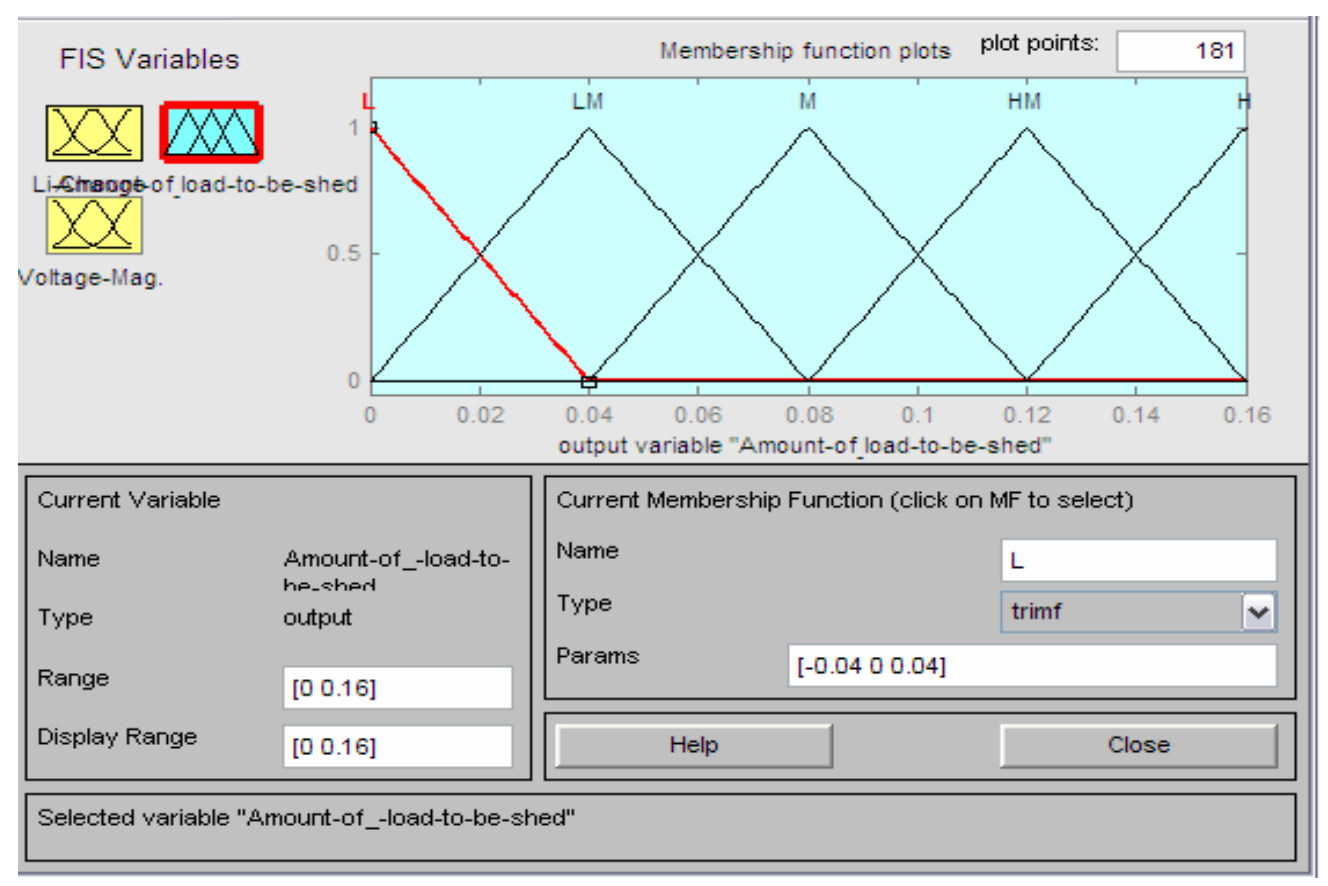

Figure 7: The output variable - Amount of load to be shed (SL) membership function

\section{Simulation Results:}

The two suggested methods in this paper are tested on the IEEE 14-bus standard system [15] (Appendix 2). The loading factor is a multiplier by which the active and reactive powers of PQ buses and the active power at the PV buses are increased keeping the voltage magnitudes of all the PV buses constant. We attempt to change the real power generation of the alternator, whose MVA capacity cannot be altered.

The threshold value depends on the power system configuration and the operating state. If this value is chosen too high, it does not ensure that the power system is maintained in the stable state. On the other hand, if it is fixed too low, the loads to be shed may be too excessive. This value is determined by a trial and error process. The algorithm is initially run by arbitrarily choosing a threshold value of 0.7 under heavy loading condition, which is just away from the voltage collapse point. The voltage magnitudes prior to load shedding may be in the range of $0.6-0.7$ p.u.

A compromise is made in choosing the threshold value. Once the threshold value is chosen for a given system, it is treated as a constant for all the loading conditions. The threshold value for the $\mathrm{L}_{\mathrm{i}}$ index is fixed as 0.12 for the IEEE 14-bus system.

Due to operating constraints there is a maximum limit to the load that can be shed at each bus (for example $80 \%$ of the initial load of the bus ) to ensure "minimum" service for consumers.

The results are obtained by using the Newton-Raphson load flow analysis simulation in MATLAB Power System Analysis Toolbox, (PSAT) and the MATLAB Fuzzy Logic Toolbox. 


\section{Test Case: IEEE 14 bus test System}

Table (3) shows the results of the load flow solution for the IEEE 14-bus system with a 1.3 loading factor.

Table 3: Load flow solutions at 1.3 loading Factor, $L_{\text {critical }}=0.12$

\begin{tabular}{|c|c|c|c|}
\hline $\begin{array}{c}\text { Load Bus } \\
\text { No. }\end{array}$ & Voltage & Angle & L index \\
\hline V4 & 0.98846 & -0.23987 & 0.0409 \\
\hline V5 & 0.99285 & -0.2037 & 0.028 \\
\hline V7 & 1.0298 & -0.31299 & 0.0486 \\
\hline V9 & 1.0174 & -0.35119 & 0.0841 \\
\hline V10 & 1.0118 & -0.35531 & 0.0805 \\
\hline V11 & 1.0223 & -0.34848 & 0.0459 \\
\hline V12 & 1.0221 & -0.35608 & 0.032 \\
\hline V13 & 1.0152 & -0.35782 & 0.0424 \\
\hline V14 & 0.9919 & -0.37862 & 0.1008 \\
\hline
\end{tabular}

It is shown from Table (3) that the $\mathrm{L}$ index is smaller than $\mathrm{L}_{\text {critical }}$, therefore no corrective action will be taken.

Table (4) shows the results of the load flow solution for the IEEE 14-bus system with a 1.45 loading factor.

\section{Method - 1 (Mathematical calculation)}

Table 4: Load flow solutions at 1.45 loading factor, $L_{\text {critical }}=0.12$

\begin{tabular}{|l|c|c|c|c|c|l|}
\hline Bus No. & $\begin{array}{c}\text { BLS } \\
\text { Voltage }\end{array}$ & Angle & $\begin{array}{c}\text { BLS } \\
\text { Lindex }\end{array}$ & Sheddable Load & $\begin{array}{c}\text { ALS } \\
\text { Voltage }\end{array}$ & $\begin{array}{c}\text { ALS } \\
\text { index }\end{array}$ \\
\hline V4 & 0.95041 & -0.27355 & 0.0492 & & 0.95603 & 0.0482 \\
\hline V5 & 0.95843 & -0.23093 & 0.0335 & & 0.96363 & 0.0329 \\
\hline V7 & 0.98107 & -0.36304 & 0.0602 & & 0.98913 & 0.0578 \\
\hline V9 & 0.96326 & -0.41049 & 0.1057 & & 0.97246 & 0.1009 \\
\hline V10 & 0.95648 & -0.41567 & 0.1014 & & 0.96568 & 0.0971 \\
\hline V11 & 0.96848 & -0.40726 & 0.0576 & & 0.97738 & 0.0554 \\
\hline V12 & 0.96781 & -0.41675 & 0.0400 & & 0.97712 & 0.0382 \\
\hline V13 & 0.95962 & -0.41892 & 0.0533 & & 0.96984 & 0.05 \\
\hline V14 & 0.93252 & -0.44494 & 0.1278 & $3.43 \mathrm{MW}+\mathrm{j} 1.15 \mathrm{MVAR}$ & 0.94724 & 0.1151 \\
\hline
\end{tabular}

BLS $=$ before load shedding

ALS $=$ after load shedding

It is shown from Table (4) that the $\mathrm{L}_{\text {index }}$ of bus 14 is 0.1278 which is greater than 0.12 $\left(\mathrm{L}_{\text {critical }}\right)$, therefore bus 14 is the selected bus for load shedding. After load shedding of 
bus 14 , the voltage magnitude has improved to 0.94724 p.u. and the $\mathrm{L}_{\text {index }}$ has decreased to 0.1151 .

\section{Method - 2 (Fuzzy based Load shedding system)}

Determination of selected bus for load shedding using the proposed fuzzy system is shown in Table 5. It is shown from Table 5 that bus No.14 has the highest value, therefore it is selected as the selected bus for load shedding. Fig. 8 shows the FIS system for selected bus for load shedding at Bus 14 with 1.45 loading factor.

Table 5: Fuzzy output for selected bus of load shedding at loading factor 1.45

\begin{tabular}{|c|c|}
\hline Bus No. & Selected bus for load shedding \\
\hline V4 & 0159 \\
\hline V5 & 0.139 \\
\hline V7 & 0.171 \\
\hline V9 & 0.207 \\
\hline V10 & 0.204 \\
\hline V11 & 0.168 \\
\hline V12 & 0.148 \\
\hline V13 & 0.164 \\
\hline V14 & 0.219 \\
\hline
\end{tabular}

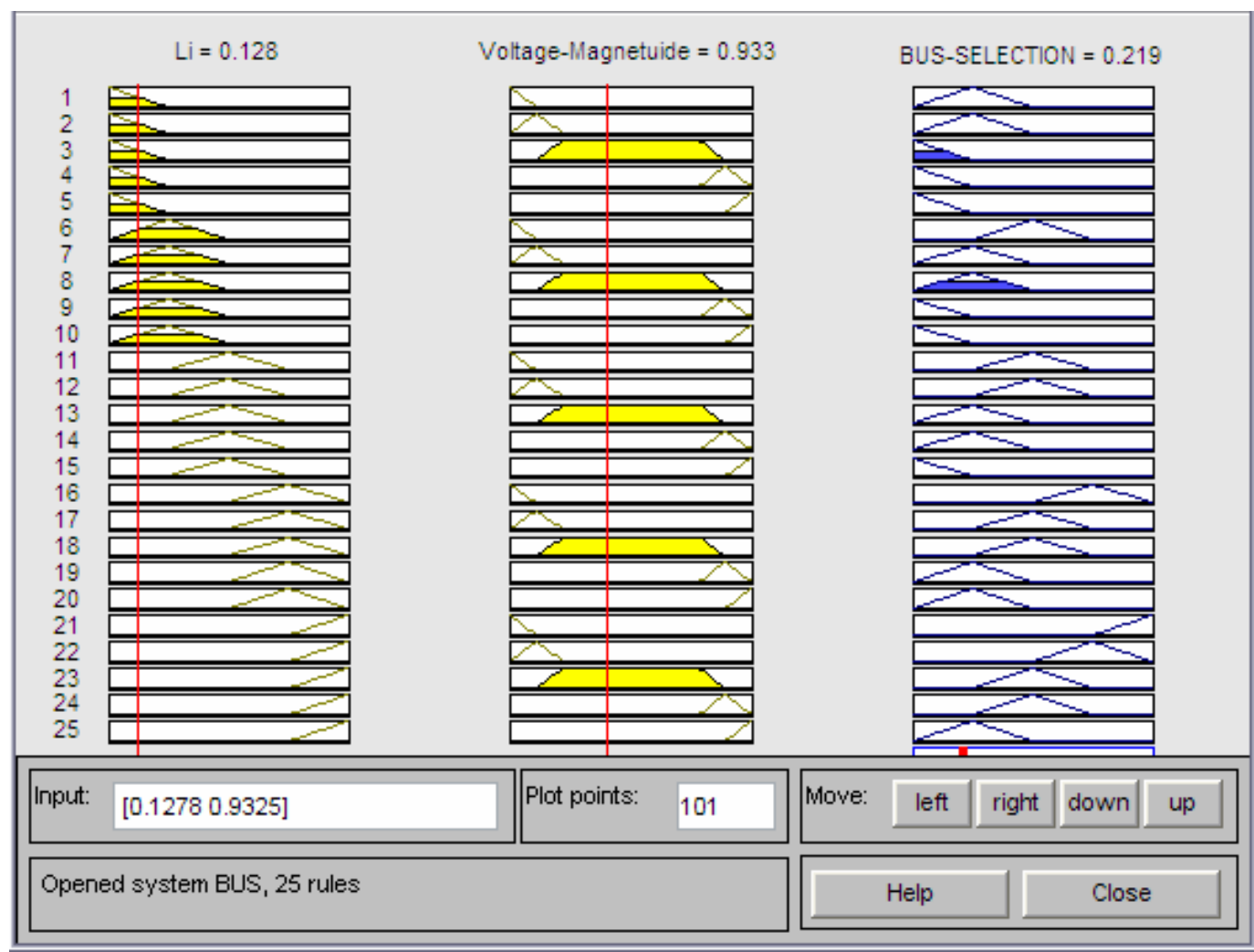

Figure 8: FIS for Selected Bus for Load Shedding at Bus (14) with 1.45 loading factor 
Using the fuzzy based Load shedding system to determine the amount of load to be shed:

The amount of load to be shed $=2.21 \mathrm{MW}+\mathrm{j} 0.7416 \mathrm{MVAR}$

The voltage profile increased at Bus 14 to 0.9421 p.u. and the voltage stability indicator decreased to 0.1195 .

Table (6) shows the results of the load flow solution for the IEEE 14-bus system with a 1.5 loading factor.

\section{Method - 1 (Mathematical calculation)}

Table 6: Load flow solutions at 1.5 loading factor, $L_{\text {critical }}=0.12$

\begin{tabular}{|l|l|l|l|l|l|l|}
\hline Bus No. & $\begin{array}{l}\text { BLS } \\
\text { Voltage }\end{array}$ & Angle & $\begin{array}{l}\text { BLS } \\
\text { L index }\end{array}$ & Sheddable Load & $\begin{array}{l}\text { ALS } \\
\text { Voltage }\end{array}$ & $\begin{array}{l}\text { ALS } \\
\text { L index }\end{array}$ \\
\hline V4 & 0.93555 & -0.28598 & 0.0525 & & 0.94936 & 0.0501 \\
\hline V5 & 0.94498 & -0.24084 & 0.0357 & & 0.95772 & 0.0341 \\
\hline V7 & 0.96197 & -0.38207 & 0.065 & & 0.98168 & 0.059 \\
\hline V9 & 0.94206 & -0.43335 & 0.1147 & & 0.96454 & 0.1027 \\
\hline V10 & 0.93483 & -0.43897 & 0.1101 & & 0.95732 & 0.0994 \\
\hline V11 & 0.94738 & -0.42991 & 0.0626 & & 0.96918 & 0.0568 \\
\hline V12 & 0.94652 & -0.44018 & 0.0434 & & 0.96927 & 0.0388 \\
\hline V13 & 0.93785 & -0.44254 & 0.0578 & & 0.96275 & 0.0498 \\
\hline V14 & 0.90925 & -0.47075 & 0.1392 & $7.95 \mathrm{MW}+\mathrm{j} 2.66 \mathrm{MVAR}$ & 0.94469 & 0.1086 \\
\hline
\end{tabular}

It is shown from Table (6) that the $\mathrm{L}_{\text {index }}$ of bus 14 is 0.1392 which is greater than 0.12 $\left(\mathrm{L}_{\text {critical }}\right)$, therefore bus 14 is the selected bus for load shedding. After load shedding of bus 14 , the voltage magnitude has improved to 0.94469 p.u. and the $\mathrm{L}_{\text {index }}$ has decreased to 0.1086 .

\section{Method - 2 (Fuzzy based Load shedding system)}

Determination of selected bus for load shedding using the proposed fuzzy system is shown in Table 7. It is shown from Table 7 that bus No.14 has the highest value, therefore it is selected as the selected bus for load shedding. Fig. 9 shows the FIS system for selected bus for load shedding at Bus 14 with 1.5 loading factor.

Table 7: Fuzzy output for selected bus of load shedding at loading factor 1.5

\begin{tabular}{|c|c|}
\hline Bus No. & Selected bus for load shedding \\
\hline V4 & 0.163 \\
\hline V5 & 0.142 \\
\hline V7 & 0.175 \\
\hline V9 & 0.212 \\
\hline V10 & 0.209 \\
\hline V11 & 0.173 \\
\hline V12 & 0.152 \\
\hline V13 & 0.168 \\
\hline V14 & 0.225 \\
\hline
\end{tabular}




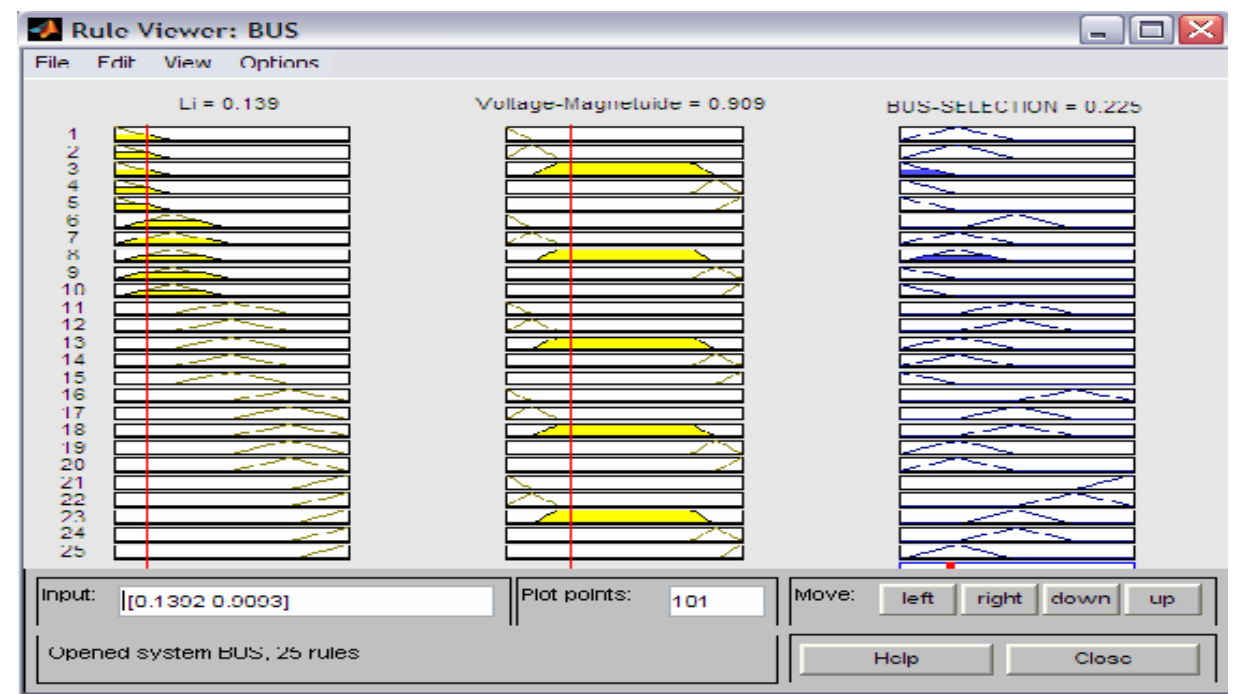

Figure 9: FIS for Selected Bus for Load Shedding at Bus (14) with 1.5 loading factor Using the fuzzy based Load shedding system to determine the amount of load to be shed:

Amount of Load to be shed $=6.89 \mathrm{MW}+\mathrm{j} 2.304 \mathrm{MVAR}$

The voltage profile increased at Bus 14 to 0.9402 p.u and the voltage stability indicator decreased to 0.1123 .

Table (8) shows the results of the load flow solution for the IEEE 14-bus system with a 1.6 loading factor.

\section{Method - 1 (Mathematical calculation)}

Table 8: Load flow solutions at 1.6 loading factor, $L_{\text {critical }}=0.12$

\begin{tabular}{|l|l|l|l|l|l|l|}
\hline Bus No. & $\begin{array}{l}\text { BLS } \\
\text { Voltage }\end{array}$ & Angle & $\begin{array}{l}\text { BLS } \\
\text { L index }\end{array}$ & Sheddable Load & $\begin{array}{l}\text { ALS } \\
\text { Voltage }\end{array}$ & $\begin{array}{l}\text { ALS } \\
\text { L index }\end{array}$ \\
\hline V4 & 0.9 & -0.31365 & 0.0608 & & 0.92586 & 0.0557 \\
\hline V5 & 0.9133 & -0.26256 & 0.0407 & & 0.93659 & 0.0379 \\
\hline V7 & 0.91682 & -0.42587 & 0.0767 & & 0.95273 & 0.0657 \\
\hline V9 & 0.89192 & -0.48672 & 0.1374 & & 0.93277 & 0.1147 \\
\hline V10 & 0.88362 & -0.49348 & 0.1323 & & 0.92461 & 0.1117 \\
\hline V11 & 0.89749 & -0.48278 & 0.0748 & & 0.93727 & 0.0639 \\
\hline V12 & 0.89614 & -0.49506 & 0.0521 & & 0.9375 & 0.0433 \\
\hline V13 & 0.88635 & -0.49787 & 0.0695 & & 0.93117 & 0.0547 \\
\hline V14 & 0.8542 & -0.53166 & 0.1683 & 11.92 MW +j 4 MVAR & 0.91583 & 0.1141 \\
\hline
\end{tabular}

The program indicates that 17.18 MW and 5.765 MVAR should be shed but with these amount the total powers to be shed in bus 14 is greater than that allowed (total powers to be shed reach $80 \%$ of the initial base load. Therefore the program decides to shed only 11.92 MW and 4 MVAR at this bus, after solving load flow if this bus with highest indicator therefore in the next step (the next maximum value indicator) is selected to carry out load shedding. 


\section{Method - 2 (Fuzzy based load shedding system)}

Determination of selected bus for load shedding using the proposed fuzzy system is shown in Table 9. It is shown from Table 9 that bus No.14 has the highest value, therefore it is selected as the selected bus for load shedding. Fig. 10 shows the FIS system for selected bus for load shedding at Bus 14 with 1.6 loading factor.

Table 9: Fuzzy output for selected bus of load shedding at loading factor 1.6

\begin{tabular}{|c|c|}
\hline Bus No. & Selected bus for load shedding \\
\hline V4 & 0.171 \\
\hline V5 & 0.149 \\
\hline V7 & 0.186 \\
\hline V9 & 0.224 \\
\hline V10 & 0.244 \\
\hline V11 & 0.184 \\
\hline V12 & 0.162 \\
\hline V13 & 0.237 \\
\hline V14 & 0.41 \\
\hline
\end{tabular}

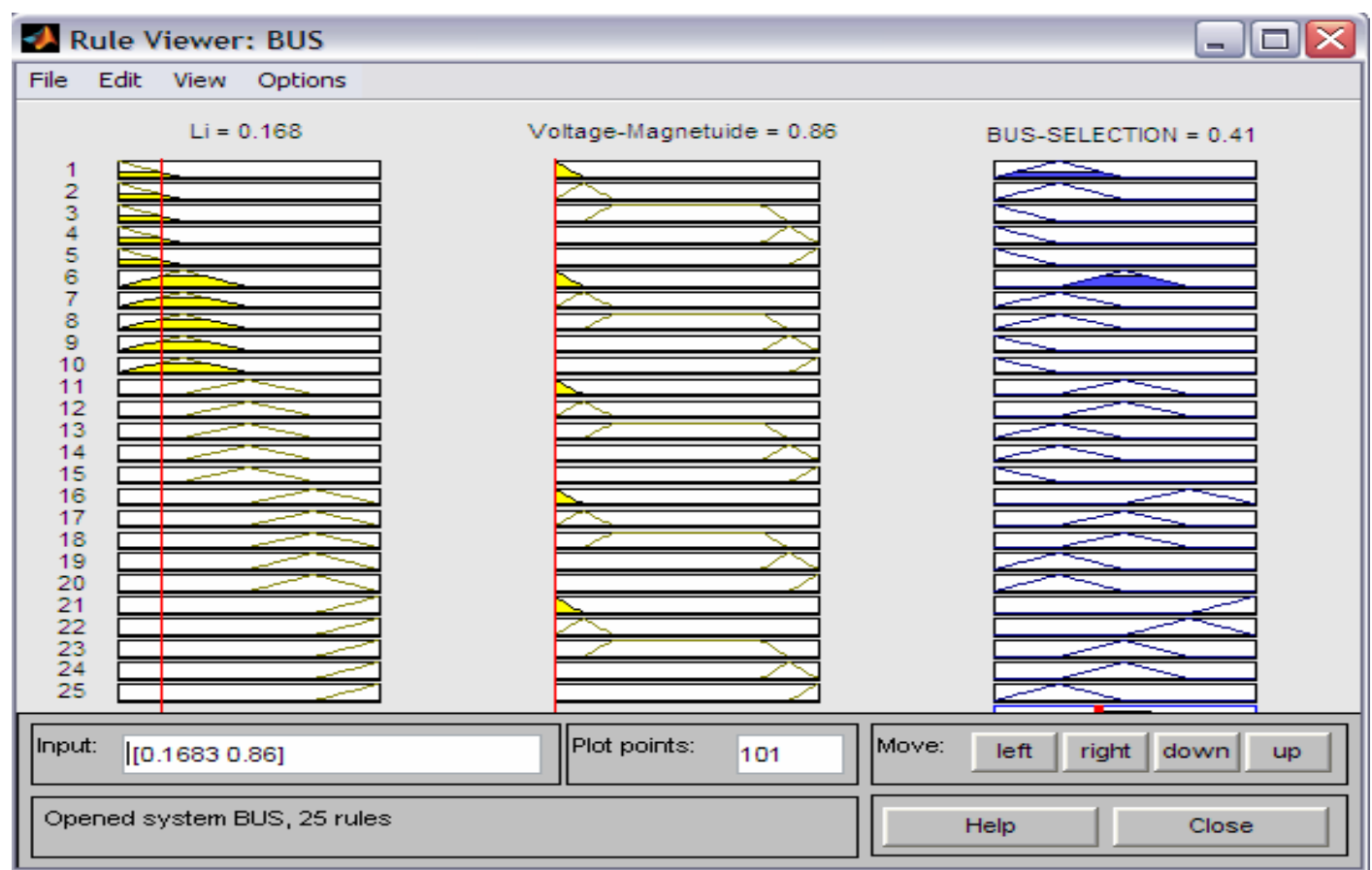

Figure 10: FIS for Selected Bus for Load Shedding at Bus (14) with 1.6 loading factor

Using the fuzzy based load shedding system to determine the amount of load to be shed: Amount of Load to be shed =11.59 MW+ j 3.9 MVAR

The voltage profile increased at Bus 14 to 0.91427 p.u and the voltage stability indicator decreased to 0.1155 . 
It is noticed from the previous results that the fuzzy based load shedding method is most appropriate to compute the sheddable load, and it directly predicts the amount of load to be shed at the selected bus. Also this scheme shows an improvement in the bus voltage profile, in addition to enhancing the voltage stability of the system.

\section{Conclusion:}

Two algorithms for load shedding to avoid voltage collapse have been presented in this paper. A simple and new method is developed to determine the location and quantity of load to be shed in order to prevent the system voltage from going to the unstable situation.

The values of the sheddable load powers are computed by mathematical and fuzzy logic techniques. It is observed that the net sheddable loads from the mathematical method are slightly higher than that obtained by the fuzzy logic method. Both of the mathematical and the fuzzy logic techniques show considerably improvement in voltage profile (VP) besides enhancing voltage stability (VS).

\section{References:}

[1] C. Barbier and J.P. Barret, 'An Analysis of Phenomena of Voltage Collapse on a Transmission System', Revue General de L' Electricitie, Special CIGRE Issue, July (1980), pp. 3-21.

[2] C. Subramani, Subhransu Sekhar Dash, Subhendu Pati and M. Arunbhaskar 'Voltage Collapse Prediction and Optimal Location for Stability Enhancement in Power Systems based on Single Contingency Scenario', European Journal of Scientific Research, Vol. 50, No. 4, (2011), pp. 554-563.

[3] M. Z. El-Sadek, G. A. Mahmoud, M. M. Dessouky and W. I. Rashed, 'Optimum Load Shedding for Avoiding Steady State Voltage Instability', Electric Power System Research, Vol. 50, No. 2, (1999), pp. 119-123.

[4] N. Sadati, T. Amraee and A. M. Ranjbar, 'A Global Particle Swarm-based Simulated Annealing Optimization Technique for Under-Voltage Load Shedding Problem', Applied Soft Computing, Vol. 9, No. 2, (2009), pp. 652-657.

[5] L. Arya, V. Pande and D. Kothari, 'A Technique for Load Shedding based on Voltage Stability Consideration', International Journal of Electrical Power and Energy Systems, Vol. 27, No. 7, (2005), pp. 506-517.

[6] T. Quoc Taun, J. Fandino, N. Hadjsaid, and J. C. Sabon-nadiere and H. Vu, 'Emergency Load Shedding to Avoid Risks of Voltage Instability using Indicators', IEEE Transactions on Power Systems, Vol. 9, No. 1, (1994), pp. 341-351.

[7] P. Kessel and H. Glavitsch, 'Estimating the Voltage Stability of a Power System', IEEE Transactions on Power Delivery, Vol. 1, No. 3 (1986), pp. 346-354.

[8] C. W. Taylor, 'Concept of Under Voltage Load Shedding for Voltage Stability', IEEE Transactions on Power Delivery, Vol. 7, No. 2, (1992), pp. 480-488. 
[9] A. R. Minhat, M. M. Othman, M. K. Idris, N. Hamzah, Z. Zakaria and I. Musirin, 'Multi-Step Load Shedding Scheme for Voltage Security Assessment Considering System Disturbances', $7^{\text {th }}$ WSEAS International Conference on Application of Electrical Engineering (AEE'08), Trondheim, Norway, July 2-4, 2008.

[10] F. Casamatta, D. Cirio, D. Lucarella, S. Massucco, R. Salvati and M. Sforna, 'Management of Interruptible Loads for Power System Security and Operation', IEEE Power Engineering Society Summer Meeting, Vol. 2, July 2002, pp. 880 -885.

[11] J. Momoh and K. Tomsovic, 'Overview and Literature Survey of Fuzzy Set Theory in Power Systems', IEEE Transactions on Power Systems, Vol. 10, No. 3, (1995), pp. 1676-1690.

[12] S. Shankar and T. Ananthapadmanabha, 'Fuzzy Approach to Critical Bus Ranking under Normal and Line Outage Contingencies', International Journal on Soft Computing, Vol. 2, No. 1, (2011), pp. 59-69.

[13] J. Sasikala and M. Ramaswamy, 'Fuzzy based Load Shedding Strategies for Avoiding Voltage Collapse', Applied Soft Computing, Vol. 11, (2011), pp. 3179-3185. [14] P. A. Raj and M. Sudhakaran, 'Optimum Load Shedding in Power System Strategies with Voltage Stability Indicators', Scientific Research, Vol. 2, (2010), pp. 1221.

[15] Power System Test Case Archive. Available from: www.ee.washington.edu. 